\title{
In reply: the agreement between venous and arterial blood gas in critical care and ward patients: is there a need to stratify for shock?
}

\author{
Claudio M. Martin, MSc, MD, FRCPC, CCPE $@$ - Fran Priestap, MSc
}

Received: 23 January 2018/Accepted: 23 January 2018/Published online: 5 February 2018

(C) Canadian Anesthesiologists' Society 2018

We thank Drs. Wong and Joseph for their comments ${ }^{1}$ regarding our paper ${ }^{2}$ on the agreement between arterial and venous blood gases. We concur with their concern that the agreement we reported may be affected by the condition of the patient. They suggested that we add a stratified analysis based on high lactate or low $\mathrm{pH}$ values. However, one of the strengths of the Bland-Altman plots is that visual inspection shows agreement is similar across the entire range of $\mathrm{pH}$ and lactate. There is a possibility that high lactate and low $\mathrm{pH}$ values are discordant within a patient and that agreement may be different in this subset. Using the thresholds of lactate $>4 \mathrm{mEq} \cdot \mathrm{L}^{-1}$ and $\mathrm{pH}<7.25$ suggested by Drs. Wong and Joseph, this occurred in only $14 \%$ and $5 \%$ of patients in the intensive care unit and the ward, respectively. This sample size is too small to permit further meaningful interpretation. In preparing the paper, we also considered that patients with greater illness severity would have more blood gas sampling. The agreement was the same regardless of the number of samples (data not presented).

As we state in the conclusion of our paper, the clinical circumstances need to be considered. In a patient with suspected shock and tissue hypoperfusion, it may be warranted to obtain an initial paired arterial and venous sample, if possible, for confirmation of agreement. The patient may then be managed accordingly.

Conflict of interest None declared.

Editorial responsibility This submission was handled by Dr. Hilary P. Grocott, Editor-in-Chief, Canadian Journal of Anesthesia.

\section{References}

1. Wong $M L$, Joseph JW. The agreement between venous and arterial blood gases in critical care and ward patients: is there a need to stratify for shock? Can J Anesth 2018. DOI: https://doi.org/10. 1007/s12630-018-1078-2.

2. Martin CM, Priestap F. Agreement between venous and arterial blood gas analysis of acid-base status in critical care and ward patients: a retrospective cohort study. Can J Anesth 2017; 64: 1138-43.
C. M. Martin, MSc, MD, FRCPC, CCPE $(\square) \cdot$ F. Priestap, MSc Schulich School of Dentistry and Medicine, Victoria Hospital, London Health Sciences Centre, Western University, London, ON, Canada

e-mail: cmartin1@uwo.ca 